\title{
An Expert System for Diagnosing and Proffering Solutions to Causes of Overheating in a Bulldozer Engine (Case Study Model D60s-6 Komatsu Products)
}

\author{
Basil O. Akinnuli ${ }^{1} \&$ Joseph O. Olaleye ${ }^{1}$ \\ ${ }^{1}$ Department of Mechanical Engineering, Federal University of Technology, Akure, Ondo State, Nigeria \\ Correspondence: Joseph O. Olaleye, Department of Mechanical Engineering, Federal University of Technology, \\ P.M.B. 1074, Akure, Ondo State, Nigeria. Tel: 234-803-764-5598. E-mail: leyequest@yahoo.com
}

Received: May 18, 2013 Accepted: October 11, 2013 Online Published: October 15, 2013

doi:10.5539/emr.v2n2p56 URL: http://dx.doi.org/10.5539/emr.v2n2p56

\begin{abstract}
Overheating is a result of some problems in the automobile engine, like improper operation or daily maintenance, local climate, machine or parts specifications inadequate to perform the specified job. These can eventually cause thermal overload, combustion of the lubricating oil on piston sliding surface, uncontrolled combustion, eventual seizure of the engine moving parts or total damage of the engine. This study identified the causes of overheating in bulldozer engine and proffered solutions to the identified causes of overheating. A software program (expert system) was developed as a tool to carry out the technical diagnosing of the causes of the overheating. A flowchart (logic chart) was also developed for troubleshooting the causes of overheating in bulldozer engine. The causes of all the failures were analyzed and their respective proffered solutions to the problems are shown and displayed. The program developed deals with the various overheating problems and obviously shows the necessity for speedy stress free and cost effective means of machine repairs. C\# (pronounced see sharp) was used as the programming language due to its versatility, efficiency as well as its user friendly interface. The importance of maintenance in manufacturing, mining and construction industries cannot be overemphasized as it goes a long way in determining productivity, efficiency and capacity of the available equipment. The probability tree diagram made the diagnosis to be fast and solutions were proffered on time. This study will enable automobile and maintenance workshops to proffer solutions to overheating problem and at the same time avoid costly damage to automotive engine and economic loss.
\end{abstract}

Keywords: overheating, bulldozer, expert system, artificial intelligence, automotive engine, cooling system, torque converter, construction, maintenance, software, work equipment

\section{Introduction}

Overheating is a condition of an automotive engine in which the operating temperature of the engine is more than the normal typical range of operating temperature (most cases from $70^{\circ} \mathrm{C}-110^{\circ} \mathrm{C}$ ) (Charles, 2002) and (Lukanin, 1990). Abdul (1996) identified causes of overheating as improper operation or daily maintenance, local climate, engine or parts specification inadequate to perform the job, defective thermostat, defective water pump, defective radiator etc and which can result to seizure of piston movement in the engine, burning of head gaskets, damage to the engine parts or complete knocking of the engine during operation.Newton et al. (1983) and Abdul (1996) specified that automotive engine temperature determined the coolant temperature and that the coolant temperature is the only controlled parameter which can be monitored through the dash board. Coolant which is the heat conducting medium of the cooling system is a mixture of water and antifreeze (freeze inhibitors and corrosion inhibitors) (Steve, 2002). Abdul (1996) specified the characteristics of good and efficient coolant as high specific and good thermal conductivity, fluidity within the temperature range of use, low freezing point, high boiling point, non- corrosive to metal, minimum degradation to non-metals, chemical stability over the temperature range of use, low flammability, high flash point, and low toxicity.

In all types of automotive engines the power is derived from the compression and expansion of the fuel with temperature as high as $2204^{\circ} \mathrm{C}$ within the combustion chamber (Stockel \& Stockel, 1990). The most frequent cooling system complaint is overheating (Newton et al., 1983). Stockel and Stockel (1982) said that to avoid overheating of automotive engine of bulldozers the cooling system must be functional. However, functional 
cooling system can promote a high volumetric efficiency of the engine, enhance maximum power output, and ensure proper combustion of the homogenous air/fuel mixture for maximum mechanical operation and reliability of the engine. Controlled removal of heat is necessary to maintain a definite temperature state of engine parts at different regimes and service condition of the engine, thereby ensuring the attainment of maximum power, efficiency and longevity of the engine at all operating conditions (Mark, 2012; Newton et al., 1983).

The components of a cooling system are radiator, radiator fan, pressure cap, reserve tank, water pump, thermostat, bypass system, freeze plugs, head gaskets, intake manifold gaskets, heater core and hoses all these components together with the coolant work to perfectly cool the automotive engine (Charles, 2002). Artificial Intelligence technology provided proficiencies for the development of computer programs for executing a variety of tasks, modeling problem solving technique by the operator or engineer and it provided a set of philosophical theories to represent the problems and also the technique for solving them (Fink et al., 1984) and (Lugar \& Stubblefield, 2004). Clancey (1984) recommended test repair as a straightforward selection tool to a successful diagnostic application in expert system and that the overview of TEST in the repair strategies included overview of TEST, verification, alternative diagnostic and sequencing. Diagnosing causes of overheating in bulldozer engine and proffering solution to the overheating problem is the focus of this study. The causes of overheating were diagnosed using the computer program and solutions were proffered to the overheating problems.

Cornelius (2002) defined expert system as a computer program that simply simulates the thought and imagination of a human expert to restively solve complex decision problems in a particular field. For several years expert system has been a reliable, dependable and convenient tool for technical diagnosing model for solving problems in different fields of engineering and technology (Lugar \& Stubblefield, 2004). Expert system has a lot of advantages such as cost efficiency, convenience, positive impact on maintenance strategy, accuracy, time saving, fast and reliable when used in making decisions (Hofmann et al., 1988). Hofmann et al. (1988) proposed and adopted two approaches to address the problems encountered in reason strategies, these approaches are Explainable Expert System (SME) which is enriched to include explicit strategic knowledge and Reconstructive Explainer (REX) which has a representation of domain rule knowledge.

Expert system has the potential of being applied to technical diagnosing of overheating problem in automotive engine. Expert system will eliminate the stress of trial-and-error, it saves time and provide optimum maintenance of the equipment (bulldozers). It will assist organization such as mining and construction industries in human capacity management for economic savings, reduces down time and prevents huge loss due to engine knock. Earthmoving equipment is the backbone of mining and construction operations upon which profitable operations and services are carried out. The developed computer program which was used for the technical diagnosing of the overheating problem was a quick means which provided immediate solutions without stress. This research is expected to make available fundamental information data and model for optimal operation, contribute to innovation in technical diagnosing of overheating in earthmoving equipment, discover technical and effective ways of minimizing down time and economic waste of equipment capacity, assist in prompt response to overheating problems, ensure total prevention of automotive engine knock and damage and complete prevention of waste of money in replacing damaged automotive engine of equipment.

\section{Method}

\subsection{Pre-investigating Approach of Overheating}

In order to investigate and address overheating problems in bulldozers engines, one needs knowledge of the machine and trouble symptoms, ability to inquire from the operator some questions about the operation of the machine or operate the machine himself to verify the negative symptoms and signs. To clarify the cause of overheating, ask the operator about the machine behavior. Also check on the performance of the machine to know if the cause of overheating is either improper operation of the equipment or attachment mismatched of job, and then advise users of the machine on proper operating methods on every kind of work and job sites. However, if causes of overheating arise from improper operation, maintenance parts or attachments, then check if proper transmission speed is selected or machine is operated in a reasonable manner. Also, verify the type of radiation if engine side cover is attached or not. If the results of the questions are abnormal, then the engineer will move into the step by step investigation method. Figure1 presents the steps to follow when investigating the system. This general framework is explained in details below: 


\begin{tabular}{l|l|}
\cline { 2 - 2 } Step 1 & Check for Maintenance Problems \\
\cline { 2 - 2 } Step 2 & Distinguish Overheating Cause By Engine Trouble from That Caused by Torque Converter \\
\cline { 2 - 2 } Step 3 & Engine Trouble Is Suspected as the Cause Of Overheating \\
\cline { 2 - 2 } Step 4 & Trouble In the Torque Converter Is Suspected as Cause of Overheating
\end{tabular}

Figure 1. Procedure for investigation of causes of overheating

A bulldozer machine model D60S-6 KOMATSU product was considered under this study. The optimum maintenance parameters values as it affects this model was considered, this assisted to know if the machine was performing optimally after corrections had been made to overcome the overheating problem(s) identified.

The parameters and values which were kept and used for corrective maintenance that will lead to optimal performance of the machines are:

Corrective Data Used for the Case Study Model D60S-6

Serial Number 18554 UP and engine serial number 114019 are:

Acceptable depression of fan belt between $12-15 \mathrm{~mm}$

Acceptable fan speed of the is between $1794-1850 \mathrm{rpm}$

Acceptable engine speed is $1600 \mathrm{rpm}$

Acceptable cracking temperature range $=75-77^{\circ} \mathrm{C}$

Acceptable fully open temperature range $=85-88^{\circ} \mathrm{C}$

Acceptable regulated oil pressure range $=3-5 \mathrm{Kg} / \mathrm{cm}^{2}$

Acceptable relieved oil pressure range $=7-8 \mathrm{Kg} / \mathrm{cm}^{2}$

These values were the values used to justify the optimal performance of the engine during troubleshooting.

\subsection{Diagnosing Steps and Procedures}

\subsubsection{Step 1: Check for Maintenance Problems}

One of the steps when investigating engine overheating problems is to check for maintenance problems. The maintenance problems to check for are typically: insufficient water level or contamination; $v$ - belt looseness due to wear or slacks; radiator core, oil level in the transmission case and oil level in steering clutch case.

If any result in Step 1 is abnormal, then correct faulty items and operate machine to check results. If the result is normal, then the cause of trouble corresponds to maintenance problem now corrected, if not, then go to step 2 .

2.2.2 Step 2: How to Distinguish Overheating Caused by Engine Trouble from That Caused by Torque Converter Trouble

Start the engine and check for movement of the engine water temperature gauge pointer and torque converter oil temperature gauge pointer. If only the engine water temperature gauge pointer moves into red range, go to step 3 . If only the torque converter oil temperature gauge pointer moves into red range or both gauge pointers move into the red range, perform stall test. After performing stall test, if stalling engine speed is in normal range, then go to step 3. If the stalling engine deviates from normal range, go to step 4.

\subsubsection{Step 3: Engine Trouble Is Suspected as the Cause of Overheating}

This can be investigated by checking the engine for defective conditions. Visually, check radiator cap seal for dirtiness or damage. If it is abnormal, clean or replace. If not, measure pressure valve for set pressure. If it is abnormal, set pressure is insufficient and valve caught on foreign particles. RCT-2A tester can be used and the standard set pressure is $0.75 \mathrm{~kg} / \mathrm{cm}^{2}$. If set pressure is normal, then measure speed of rotation of cooling fan using reflector tape on fan blade and photo tachometer, if it is abnormal, then there is worn or slippering v-belt. If v-belt is normal, measure the temperature between the upper and lower parts of radiator tank using an etched stem type thermometer or thermistor. The temperature difference should be in the range of $5-7^{\circ} \mathrm{C}$ during engine idling. You can make a quick, rough check by touching the upper and lower tank by hand to feel any temperature difference. If the temperature difference is too large, then the water pump is defective. If not, check if the thermostat valve remains closed even at cold water temperatures or if it seal contacts evenly at all points. If the 
result is abnormal, then seal is defective. If normal, simply measure thermostat cracking temperature by putting the thermostat and a thermometer in a vessel filled with water, heat the vessel and do not exceed the cracking temperature and the temperature at which the thermostat valve opens fully. If the temperature is abnormal, then thermostat is faulty. If not, then possibly cooling system is clogged with deposits (magnesium or calcium) or there is lack of driving power.

The radiator cap must not be removed while high water temperature remains in order to prevent spurting of scalding steam from the filter opening.

\subsubsection{Step 4: Trouble in the Torque Converter Is suspected as Cause of Overheating}

Measure quantity of oil drained from torque converter, it should not exceed 10 litres. If it is abnormal, then measure oil flow rate going out of the torque converter. The standard oil flow is 5 to 6 litres/minute. If the flow rate is abnormal, then the scavenging pump is defective or strainer clogged. If it is normal, then check torque converter pump-to-drive case mounting bolts for looseness. If it is normal, then torque converter inner parts are broken or seal ring leaks oil. If it is abnormal, then the bolts were loosening or broken. If necessary, re-tighten to a torque of 5.0 to $6.0 \mathrm{~kg} . \mathrm{m}$. If the torque converter inner parts are normal, then measure regulated oil pressure. If it is abnormal, then the regulator valve is defective or regulator valve is poorly seated or oil cooler clogging or regulator valve caught on foreign particles. If the measured regulated oil pressure is normal, then measure the relief oil pressure. If it is abnormal, then the relief valve is defective, relief valve poorly seating, relief valve caught foreign particles.

Oil temperature during testing is $75 \pm 5^{\circ} \mathrm{C}$.

\subsection{Flowchart for Diagnosing and Proffering Solution to Causes of Overheating}

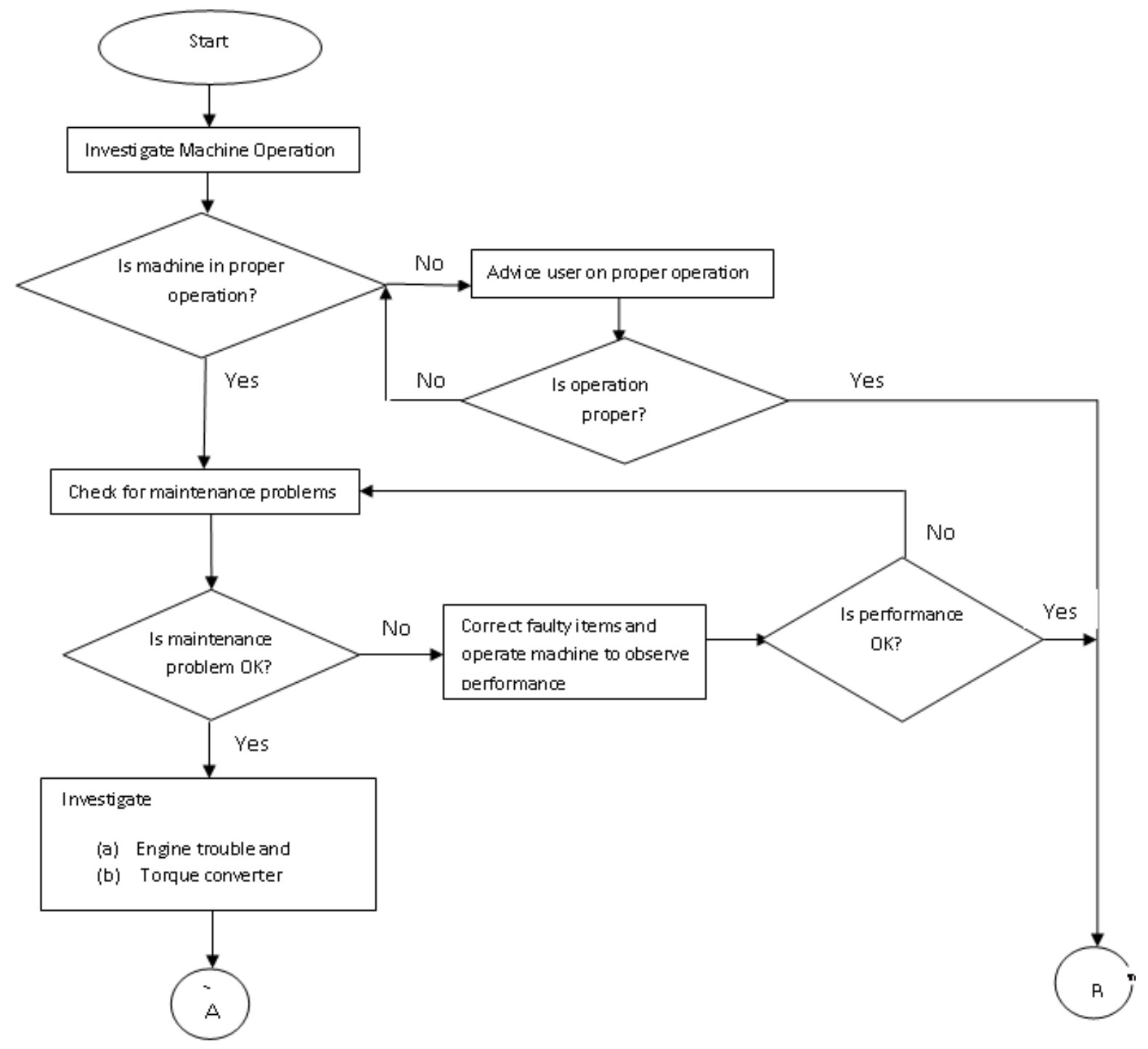




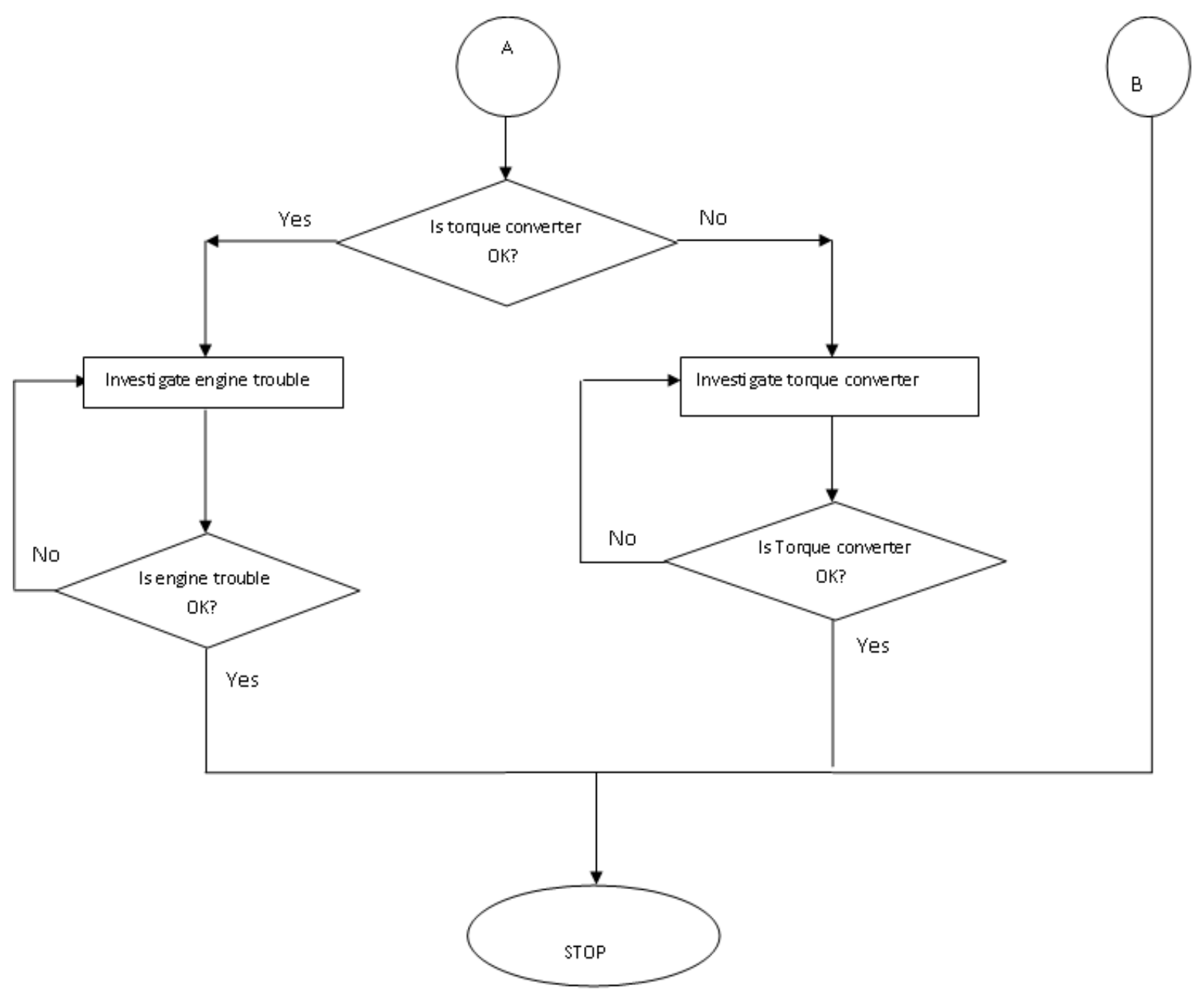

Figure 2. Expert system flow chart (Study, 2002)

\subsection{Software Development for Expert System}

To successfully run the computer program, the prerequisites that were met were operating system (windows 2000, NT, vista ultimate or windows 7), processor speed (at least 500MHz), RAM (at least 256MB), and Hard disk space (at least 2GB free) for optimum performance of the program. $\mathrm{C}$ \# (pronounced see sharp) is a multi-paradigm programming language encompassing strong typing, imperative, interactive, declarative, functional, generic, object-oriented (class-based), and component-oriented programming disciplines. It was used due to its versatility, efficiency and user friendly interface.

The operator must have a previous knowledge about bulldozer work equipment operations in order to be able to diagnose which area of the bulldozer work equipment has fault and to interpret proffered solutions.

\subsection{Case Study: Model D60S-6 KOMATSU Product}

KOMATSU LIMITED was established in 1921. The company is based in Japan and has its distributors around the world of which Nigeria is one. It is a diversified provider of industrial-use products and services. It is an international leader in the field of construction and mining equipment. By upholding quality and reliability as the most important management policy, KOMATSU is resolutely committed to providing safe, innovative products and services that best meet the needs and expectations of its customers around the world. KOMATSU provides means to support total machine life while taking safety and environment into consideration.

KOMATSU products are in various types and sizes. They are useful in different work area and sites. The work sites are mining, construction, dredging, digging, uprooting, industry, etc. In these sites, large volumes of work are carried out sometimes for hours non-stop. A bulldozer can be digging, lifting, breaking or loading etc. in a mining site for hours or dredging and expanding a river for a number of hours to meet up with a target or 
planned schedule. Construction industries cannot carry out effective and profitable services without work equipment (earthmoving equipment).

Hence, without the proper functional work equipment resulting from sound and effective maintenance strategy, activities and smooth operations will be hindered and result to production down time and low output. During operation one of the systems in the work equipment that can cause break down of machine is the cooling system as a result of overheating. In essence, overheating problem is a critical problem that cannot be overlooked thus requiring urgent attention to prevent further damage to automotive engine of earth moving equipment and eventually prevent huge economic loss.

The developed computer program used in this case study is a tool which helped in detecting, analyzing and proffering solutions to solve the overheating problems of the work equipment.

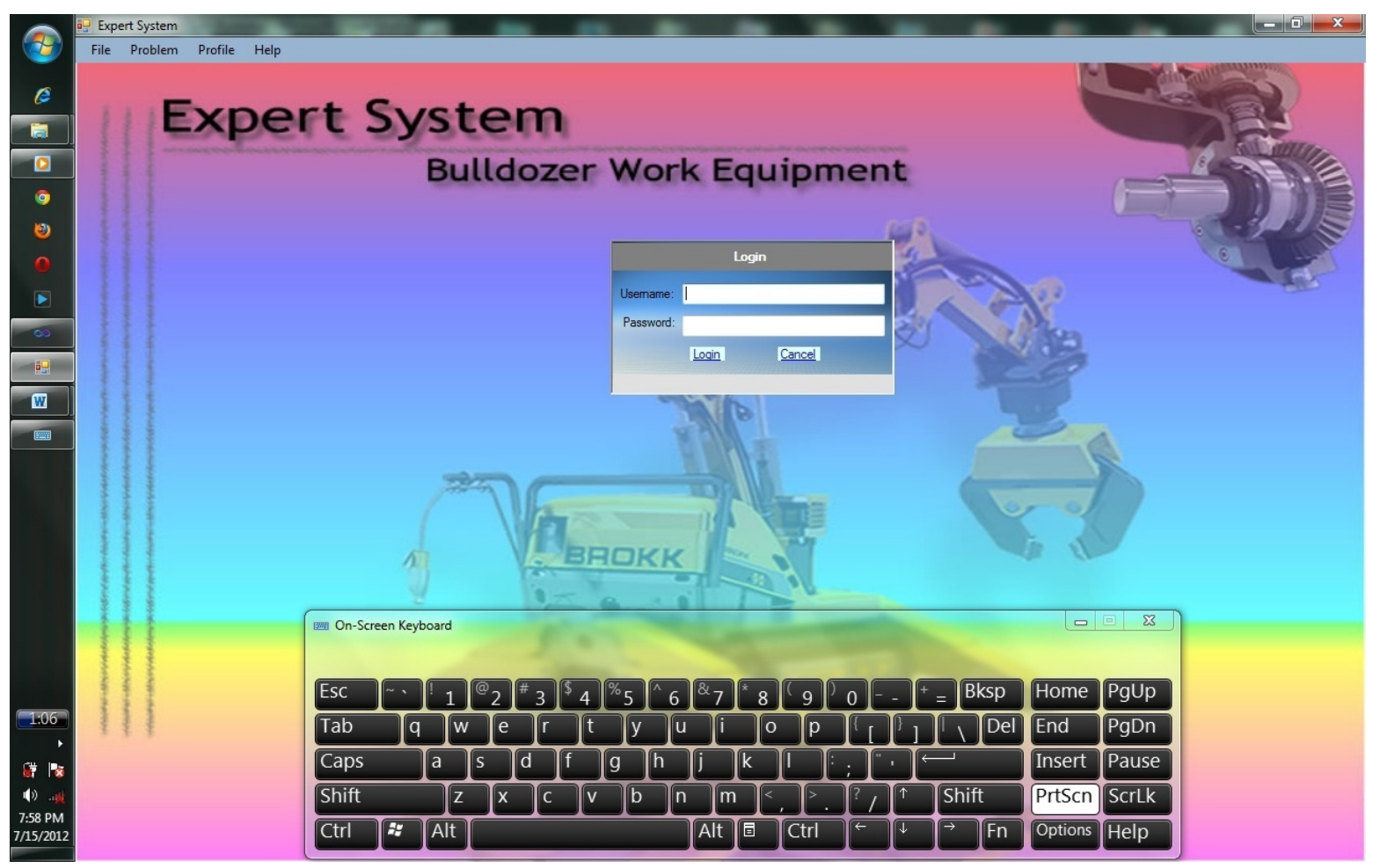

Figure 3. The login page

1. The login page for access to use the software was opened. The username was INPUT into the space and password before login was clicked to open the next interface which is the machine operation interface.

2. The machine operation suspected area that needed to be corrected was selected. The machine was operated correctly so NEXT was clicked.

3. After clicking NEXT the interface (window page) that opened provided the space to select the overheating problem, CHECK FOR MAINTENANCE PROBLEMS was clicked and then DIAGNOSED.

4. On the maintenance window page all the maintenance problems were checked and were all normal. The operator clickBACK to return to the previous page

5. On the Problem List page STEP 2 was clicked and then DIAGNOSIS, this took the operator to the Engine Operation page. At Engine Operation, the test were carried out on the engine water temperature gauge and torque converter oil temperature gauge pointers, engine speed was normal after performing stall test . The operator clicked BACK and then clicked STEP 3

6. STEP 3 opened Engine Defective window page. On this window page all the engine conditions such as radiator cap, pressure valve, cooling fan rotation speed and v-belt, water pump, thermostat valve and cracking temperature, clogging in cooling system, driving power were all checked and tested for any defects and found to be normal in comparison with the standard values . The operator then clicked BACK. 
7. At the Problem List window page STEP 4 was clicked and then DIAGNOSIS, this opened the Overheating Cause window page. On this window page all the possible overheating causes of step 4 were investigated and measured. Amount of torque converter oil, oil flow rate, transmission oil filter and torque converter drive case mounting bolts were all found to be normal and in correct operation in comparison to the standard values and specifications of the model under study, except for the pressure gauge which measured the regulated and relieved oil pressures that were not to standard values. The causes were defective regulated valve and defective relief valve.

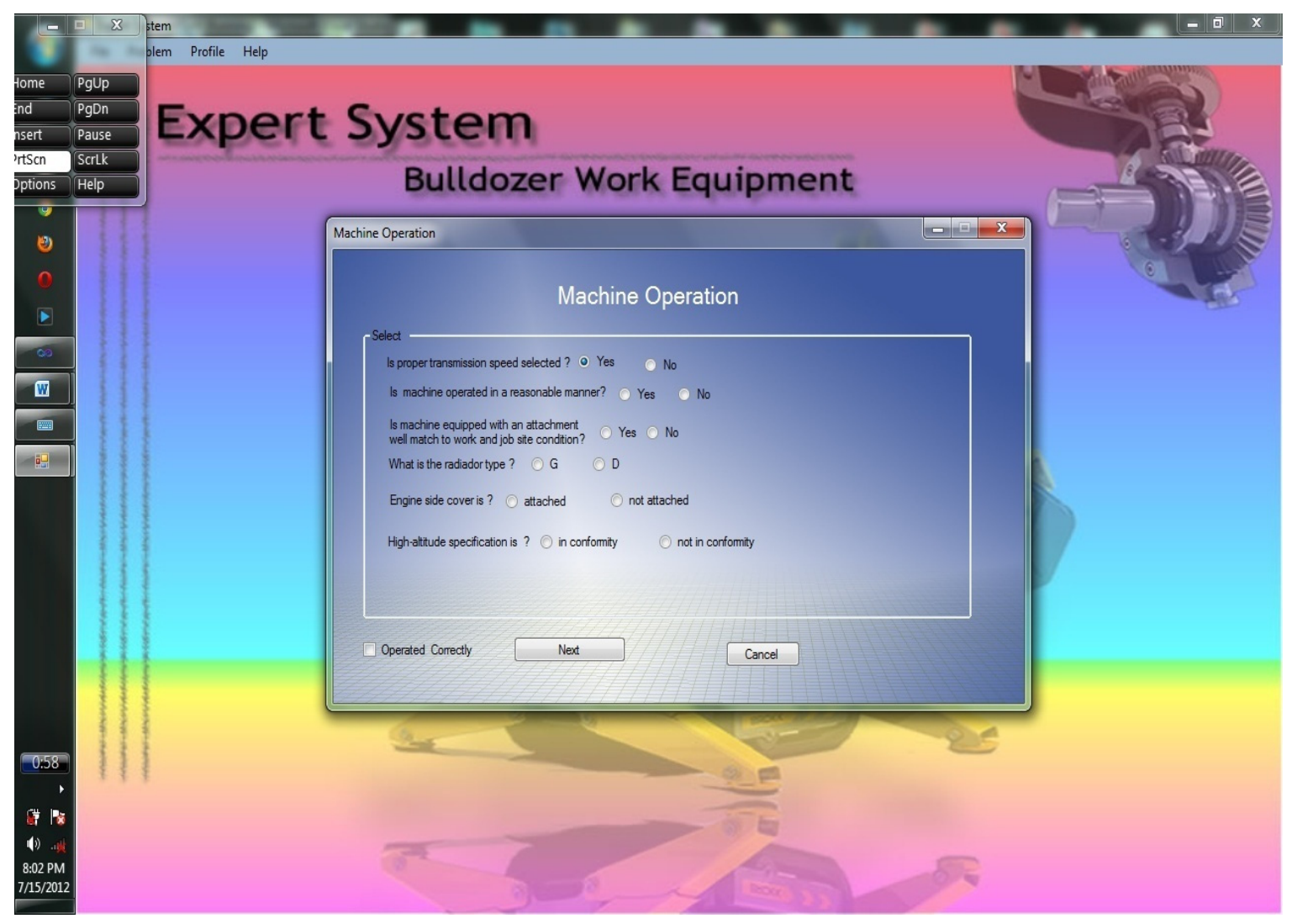

Figure 4. Summary of the various machine operations causing overheating in engines 


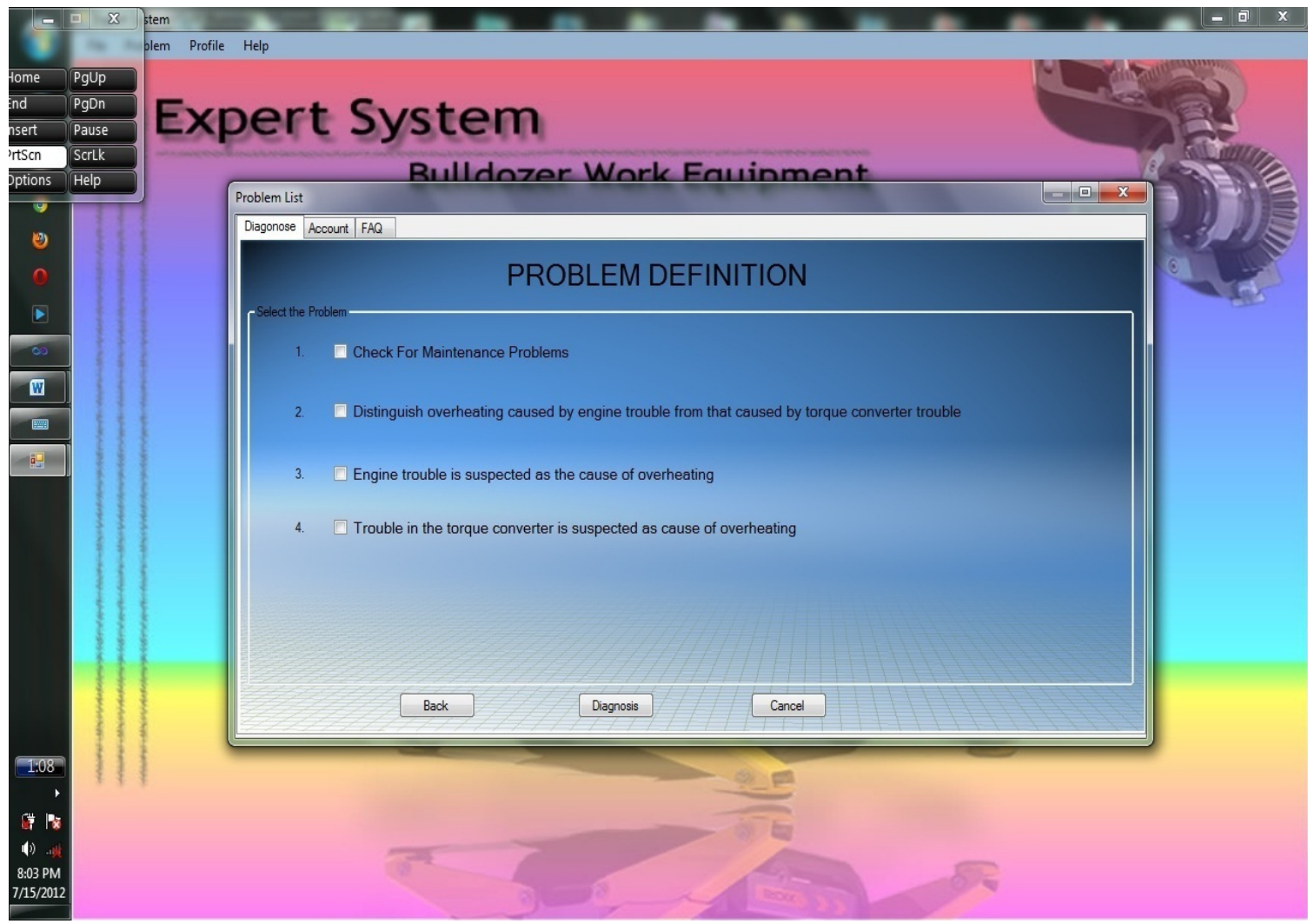

Figure 5. The problem definition page

Figure 5 describes the problem definition interface where the operator selects the step he wants to diagnose. On this interface, a selection will automatically lead the operator to the step and computer program to be used.

\section{Results}

The diagnosis and troubleshooting were carried out on the automotive engine cooling system. The procedure started from machine operation which is the simplest and easiest to diagnose to trouble in the torque converter which is the most difficult and very imprecating to diagnose.

\subsection{Analysis of the Diagnosed Steps}

In step 1 the machine operation result was normal since the operations of the machine were satisfactory without any overheating problem.

In step 2, the result of the maintenance problem was satisfactory. All the causes associated with maintenance problem were diagnosed.

Overheating caused by engine trouble was distinguished from that caused by torque converter trouble by checking the temperature gauge pointers of the water and the oil to know the temperature condition of the engine.

In step 3, the result shows that engine trouble was in normal working condition. The radiator cap pressure valve, the speed of rotation of cooling fan, thermostat crackingtemperature e.t.c. were all diagnosed.

In step 4, regulator and relief valves were found to be working at below standard values and specifications. The solutions proffered to the defective valves were outright replacement of the two valves. 


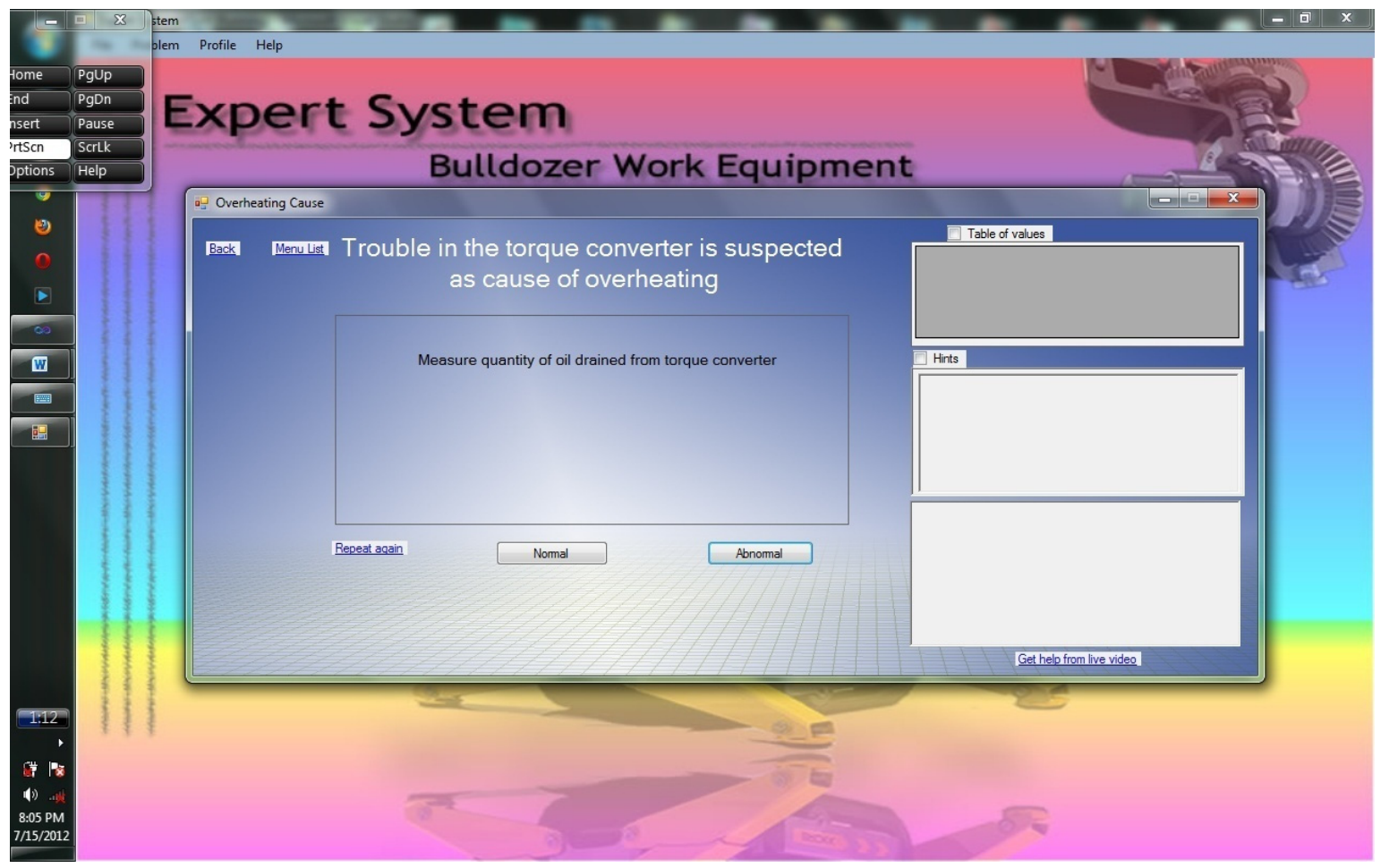

Figure 6. The interface above describes the result obtained when the torque converter trouble was suspected as the cause of overheating and diagnosed. All the possible causes in the torque converter were checked diagnosed

\section{Discussion}

\subsection{Interpretation of the Steps Diagnosis}

In step 1 the machine operation result was normal since the operations of the machine were satisfactory without any overheating problem.

In step 2, the result of the maintenance problem was satisfactory. All the causes associated with maintenance problem were diagnosed. The maintenance problem was not the cause of overheating.

Overheating caused by engine trouble was distinguihsed from that caused by torque converter trouble by checking the temperature gauge pointers of the water and the oil.

In step 3, the result shows that engine trouble as suspected was not the cause of overheating. The likely causes were checked for defective conditions but they were found to be in good working condtion.

In step 4, defective regulator and relief valves were identified as the causes of the overheating through technical diagnosing. The solutions proffered to the defective valves were outright replacement of the two valves.

\subsection{Proffered Solution}

The regulated valve was replaced and the oil pressure gauge was connected to the torque- converter regulator valve inlet port (on the output side of converter). The engine was run at high idle speed. The oil pressure gauge was measured in order to measure the regulated oil pressure. Also, the relief valve was replaced and the pressure gauge was connected to the transmission control valve outlet port (on input side of the torque converter). The engine oil pressure gauge was measured in order to measure the relieved oil pressure. The engine was run at high idle speed to test the replaced (new) valves. The regulated oil pressure was confirmed to be at $3-5 \mathrm{Kg} / \mathrm{cm}^{2}$ and relieved oil pressure was $7-8 \mathrm{Kg} / \mathrm{cm}^{2}$.

The overheating problem was solved as the equipment automotive engine stopped experiencing overheating problem and worked normally.

In this case study, the research so far identified the causes of overheating in the KOMATSU product (machine model D60S-6). Step 1-3 in the problem list window page were normal and in effective operation. In no doubt, the developed computer program has tremendously helped in facilitating a systematic procedure for diagnosing 
overheating problem in work equipment. The importance of maintenance operation in manufacturing industries and production companies cannot be over-emphasized as it goes a long way in determining the productivity, efficiency and capacity of the equipment. The necessary requirements for maintenance process have changed drastically to a more complex approach, which entailed adopted maintenance strategy of a more integrated approach. Nowadays, management has become aware that maintenance will also be part of the investment decision making, thus prompting managers to take into account the sources of funding and the impact investment has on credit lines and taxes and not only to focus on upfront cost and depreciation rates. The procedures or methods used in achieving the set objectives of this research were adequate, the flowchart and computer program with the results generated were properly evaluated and tested. Therefore from the maintenance operation models identified and software developed, it is obvious that that the rate at which there will be engine failures on the field of mining and construction will largely reduce. Finally the set objectives of the research have been achieved and the software developed will find its application in all maintenance, mining, construction and manufacturing companies for planning and control policy for optimum performance and productivity.

Based on the results of this study, these recommendations become necessary

i) At the initial stage of the data collection, effort should be made to input accurate and detailed information about the cooling system parameters and parts

ii) Further research work should be done on the optimization of maintenance operation that could cause overheating in engines

iii) Expert system for diagnosing overheating problem is recommended for use in construction, mining, manufacturing and all earthmoving equipment maintenance workshops.

\section{References}

Abdul, A. O. (1996). The Development of A Testing Equipment for An Automotive Engine Water Cooling System. M. Eng Project Report (pp. 22-34). Department of Mechanical Engineering, University of Lagos, Nigeria.

Charles, O. (2002). A Short Course on Cooling System. Troubleshooting Professional Magazine, 6(4).

Clancey, W. (1984). Details of the Revised Therapy Algorithm. In B. G. Buchanan, \& E. H. Shortliffe (Eds.), Rule Based Expert Systems. Addison Wesley.

Cornelius, T. L. (2002). Expert System: The technology of knowledge management and decision making for the $21^{\text {st }}$ century. Addison Wesley.

Fink, P. K., Lusth, J. C., \& Duran, J. W. (1984). A General Expert System Design for Diagnostic Problem Solving. In Proceedings of Institute of Electrical Electronics Engineering (IEEE) Workshop. Principles of Knowledge Based Systems.

Hofmann, M., Caviedes, J., Bourne, J., \& Beale, G. B. (1988). Building Expert Systems for Repair Domains. Expert Systems. Prentice Hall

Lugar, G., \& Stubblefield, W. (2004). Artificial Intelligence: Structures and Strategies for Complex Problem Solving (5th ed.). The Benjamin/Cummings Publishing Company, Inc.

Lukanin, V. N. (1990). Internal Combustion Engine. MIR Publishers, Moscow.

Mark, S. (2012). Automotive Heating and Air-Conditioning (5th ed.). Delmar Publishers Incorporation.

Newton, K., Steeds, W., \& Garrett, T. K. (1983). The Motor Vehicle (10th ed.). Butterworths.

Steve, L. (2002). Automotive Cooling System Maintenance and Repair. Troubleshooting Professional Magazine, $6(4)$.

Stockel, M. W., \& Stockel, M. T. (1990). Auto Mechanics Fundamentals, the Good Heart. Willcox Company Incorporation.

\section{Copyrights}

Copyright for this article is retained by the author(s), with first publication rights granted to the journal.

This is an open-access article distributed under the terms and conditions of the CreativeCommons Attribution license (http://creativecommons.org/licenses/by/3.0/). 